COVER ESSAY

\title{
Beware the rooster: smokeless tobacco companies who claim they want to help
}

\section{Myers}

Tobacco Control 2003;12:342-342

\section{It should not be assumed that smokeless tobacco manufacturers share our public health goals}

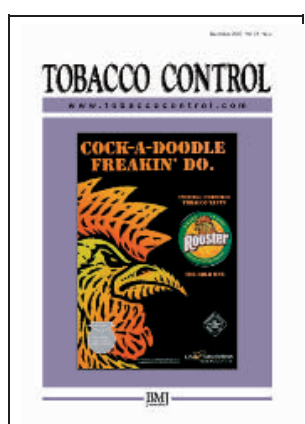

Correspondence to: Matthew Myers, President, Campaign for TobaccoFree Kids, 1400 I Street, NW, Suite 1200 Washington, DC' 20016, USA; mmyers@ TobaccoFreeKids.org
$\mathrm{T}$ he rooster that dominates the United States Smokeless Tobacco Company's (USSTC) advertisement that adorns this month's cover serves as a wake up call to those involved in the debate about the use of snus or smokeless tobacco as a potential harm reduction tool. The ad serves as a reminder that this debate cannot take place in the abstract or assume that the manufacture, marketing, regulation, or use of snus will take place in environments identical to those that exist in Sweden. It should also not be assumed that smokeless tobacco manufacturers share our public health goals. They do not, as this ad vividly demonstrates.

This advertisement ran in a magazine read by millions of American teens at the time that the USSTC was preparing to request the US Federal Trade Commission to give its approval for USSTC to claim in its ads that its smokeless tobacco products are safer than cigarettes.

USSTC, the manufacturer of Skoal and Copenhagen, claimed that its goal was to convince addicted smokers who could not or would not quit smoking to switch to smokeless tobacco in order to reduce their risk of disease. When USSTC was asked if this ad was targeted to committed smokers and whether it would agree not to make health claims in these types of youth oriented advertisements, USSTC squirmed uncomfortably, and said that if the government granted its request, there would be nothing to prevent it from running its health claims in ads like this one or in magazines with a large youth audience.

Several weeks later USSTC informed us that the ad on the cover would never run again, presumably because of the concerns we had raised that it was targeted at adolescent boys, and because of USSTC's desire to prove its professed intention to focus its marketing on convincing addicted smokers to switch. Thus, imagine our surprise when we subsequently opened up a sports magazine popular among adolescent boys only to discover the identical ad with one change and one change only. The title of the ad had been changed from "Cock-a-doodle Freakin' Do" to "Where's the Chicks?” (fig l).
Our experience with USSTC is a cautionary tale. The debate about the use of smokeless tobacco use takes place in the real world. In the USA, for example, there are no laws to prevent a smokeless tobacco manufacturer from using advertising to make their products more appealing to young non-tobacco users. This is precisely what happened 20 years ago when USSTC combined a massive marketing effort with claims comparing their smokeless products to cigarettes. The result was not fewer smokers, it was more smokeless tobacco users. In the USA there are also no laws governing the content of smokeless tobacco products to ensure that they have low levels of nitrosamines or other harmful substances. As a result, smokeless tobacco products in the USA do not resemble those marketed in Sweden.

Perhaps, most importantly, our experience reminds us that the top priority of smokeless tobacco manufacturers is to maximise sales and profits, not save lives. They will do whatever they are allowed to do to sell more smokeless tobacco, including using health related claims to appeal to smokers and non-smokers alike.

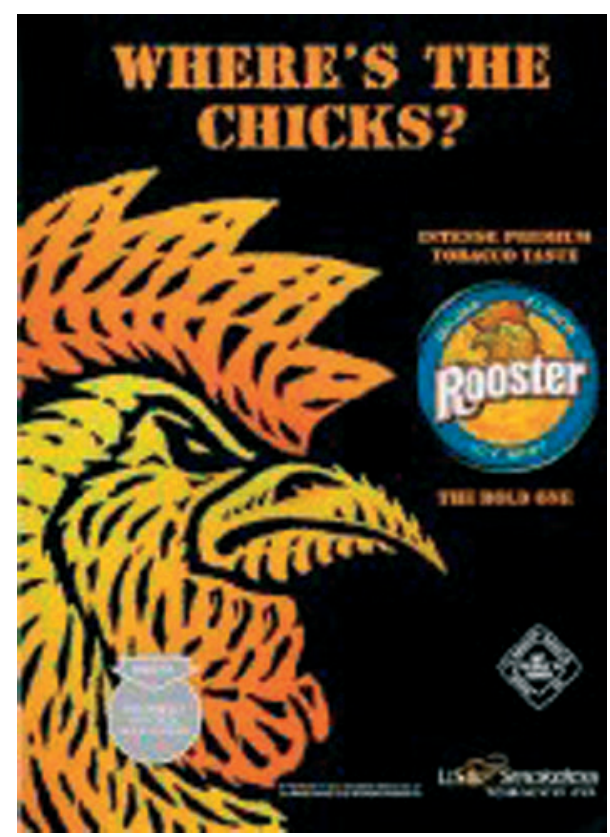

Figure 1 Amended advertisement run by the United States Smokeless Tobacco Company. 